IN a previous work we have shown that heparin, in the presence of ozone $\left(\mathrm{O}_{3}\right)$, promotes a dose-dependent platelet aggregation, while after $\mathrm{Ca}^{2+}$ chelation with citrate, platelet aggregation is almost negligible. These results led us to think that aggregation may enhance the release of platelet components. We have here shown that indeed significantly higher amount of platelet-derived growth factor (PDGF), transforming grow th factor $\beta 1$ (TGF- $\beta 1$ ) and interleukin-8(IL-8) are released in a dose-dependent manner after ozonation of heparinised platelet-rich plasma samples. These findings may explain the enhanced healing of torpid ulcers in patients with chronic $\operatorname{limb}$ ischemia treated with $\mathrm{O}_{3}$ autohaemoteraphy $\left(\mathrm{O}_{3}\right.$-AHT).

Key words: ozone, platelets, aggregation, grow th factors, inteleukin-8

\section{Studies on the biological effects of ozone: 10. Release of factors from ozonated human platelets}

\section{G. Valacchi and Velio Bocci ${ }^{\mathrm{CA}}$}

Institute of General Physiology, University of Siena, 53100 Siena Italy

\author{
${ }^{\mathrm{CA}}$ Corresponding Author \\ Tel: (+39) 577234217 \\ Fax: (+39) 39577234219 \\ Email: fisgen@unisi.it
}

\section{Introduction}

Ozone $\left(\mathrm{O}_{3}\right)$ can promote platelet aggregation particularly when heparin is used as an antic oagulant ${ }^{1}$ : this observation is not surprising in the light of previous results ${ }^{2}$ showing the role of reactive oxygen species (ROS) in platelet activation. In contrast, $\mathrm{Ca}^{2+}$ chelation with citrate markedly inhibits aggregation. ${ }^{1}$ Thus, the selection of the most appropriate anticoagulant becomes crucial when blood is intended to be used for autotransfusion ( $\mathrm{O}_{3}$-AHT) afte $\mathrm{r}$ being briefly exposed to a gas mixture composed of about $97 \%$ oxygen and $3 \%$ ozone. ${ }^{3}$ It is known that platelets are a rich source of several growth factors such as platelet-derived grow th factor (PDGF), ${ }^{4}$ trans forming grow th factor $\beta 1$ (TGF- $\beta 1),{ }^{5}$ eicosanoids and interleukins (IL). ${ }^{6}$

PDGF and TGF $\beta 1$ promote wound healing and if, in the course of $\mathrm{O}_{3}$ AHT, the reinfused platelets increase their release, it can be envisaged how this complementary therapy, besides improving oxygenation of hypoxic tissues, enhances healing of torpid ulcers in chronic limb ischemia. For this reason we have now investigated whether the use of heparin or citrate added to blood, before ozonation, affects the release of platelet factors differently.

\section{Materials and methods}

Ozone generation and measurement

$\mathrm{O}_{3}$ was generated from medical grade $\mathrm{O}_{2}$ using electrical corona arc discharge in the last generation
$\mathrm{O}_{3}$ generator (Model Ozonosan PM100K, Hansler GmbH, Iffezheim, Germany) which allows the gas flow rate and $\mathrm{O}_{3}$ concentration to be controlled in real time by photometric determination at $253.7 \mathrm{~nm}$ as recommended by the Standardisation Committee of the International $\mathrm{O}_{3}$ Association.

\section{Reagents}

Anticoagulants were either heparin (calcium salt, $30 \mathrm{IU} / \mathrm{ml}$ blood) normally used for therapeutic purposes (Calciparina, Italfarmaco) or ACD (Citric acid, $\mathrm{Na}$ citrate, Glucose) (Haemonetics, Braintree, USA). Adenosine diphosphate (ADP) was a product from Sigma Chemical Co. (St. Louis, Mo) and for the studying aggregation a $0.5 \mathrm{mM}$ solution was freshly prepared.

\section{Preparation of platelet rich plasma (PRP) samples}

Both ACD and heparinised platelet rich plasma (PRP) were prepared from the same blood samples $(60 \mathrm{ml})$ draw $n$, after informed consent, from five fasting (12 hours) non-smokers volunteers between the ages of 23 and 27 years, who were considered to be healthy and had not ingested platelet-active medication for at least two weeks.

Nine parts blood were anticoagulated with either one part ACD or with one part of saline containing heparin so that its final concentration was $30 \mathrm{IU} / \mathrm{ml}$. Blood was centrifuged at $200 \times \mathrm{g}$ for $20 \mathrm{~min}$ and platelets were measured with a Coulter counter. An 
average platelet count of $3 \times 10^{8} / \mathrm{ml}$ plasma was used. A furthe $r$ centrifugation of PRP at $6000 \times \mathrm{g}$ for $15 \mathrm{sec}$ gave a platelet-containing pellet and a supernatant platelet-free plasma used for biochemical determinations.

\section{$\mathrm{O}_{2}$ and $\mathrm{O}_{3}$ delivery to biological samples}

A predetermined volume of the $\mathrm{O}_{2} / \mathrm{O}_{3}$ gas mix ture at three $\mathrm{O}_{3}$ concentrations $(20,40$ and $80 \mu \mathrm{g} / \mathrm{ml}$ per ml of PRP) was collected with a silicone coated disposable syringe and immediately introduced into a second syringe containing an equivalent volume of PRP via a ' $y$ ' connector. Final gas pressure remained at normal atmospheric pressure. In order to obtain reproducible results, it needs to be emphasised that $\mathrm{O}_{3}$ is a very reactive gas so that extremely rapid and precise handling is required. The PRP samples were gently but continuously mixed with the gas for up to $30 \mathrm{sec}$ and afterwards they were dispensed into test tubes for various analysis. Control samples were either untreated or mixed with an equal volume of $\mathrm{O}_{2}$. After incubation each sample was immediately centrifuged at $10,000 \times \mathrm{g}$ for $20 \mathrm{~min}$ at $2^{\circ} \mathrm{C}$ and the supernatant platelet-free plasma was used for determining variations of thiobarbituric acid reactive substances (TBARS), ${ }^{7}$ the total antioxidant status $(\mathrm{TAS})^{8}$ and of protein thiol groups (PTG) according to Hu. ${ }^{9}$ An aliquot of the plasma samples was frozen at $-70^{\circ} \mathrm{C}$ until determinations of several factors specified below were carried out.

\section{Biochemical determinations}

1. Thiobarbituric acid reactive substances (TBARS) determination: in order to evaluate the relevance of lipid peroxidation, TBARS were assessed according to Pompella et al. ${ }^{7}$

2. Total antioxidant status (TAS) in plasma samples was assessed according to Rice-Evans and Miller. ${ }^{8}$

3. Protein thiol groups (PTG) were measured in plasma according to $\mathrm{Hu}^{9}$ using procedure 1 with 5,5'-Dithio-bis (2-Nitrobenzoic acid) DTNB dissolved in absolute methanol.

\section{Immunoassay}

Immunoassays of either human PDGF-AB or TGF $\beta 1$ (after activation of the latent TGF $\beta 1$ to the immunoreactive form) were carried out using Quantikine immunoassay kits produced by R\&D System (Minneapolis, USA). On the basis of preliminary tests heparinised PRPs were diluted 1:20 while citrate PRPs were diluted 1:1 only. Possible release of thromboxane $A 2$, a vasoconstrictor and aggregation-enhancer factor, was monitored by measuring the stable compound thromboxane B2 (TXB2) by using an immunoassay kit produced by R\&D Systems. For this assay,

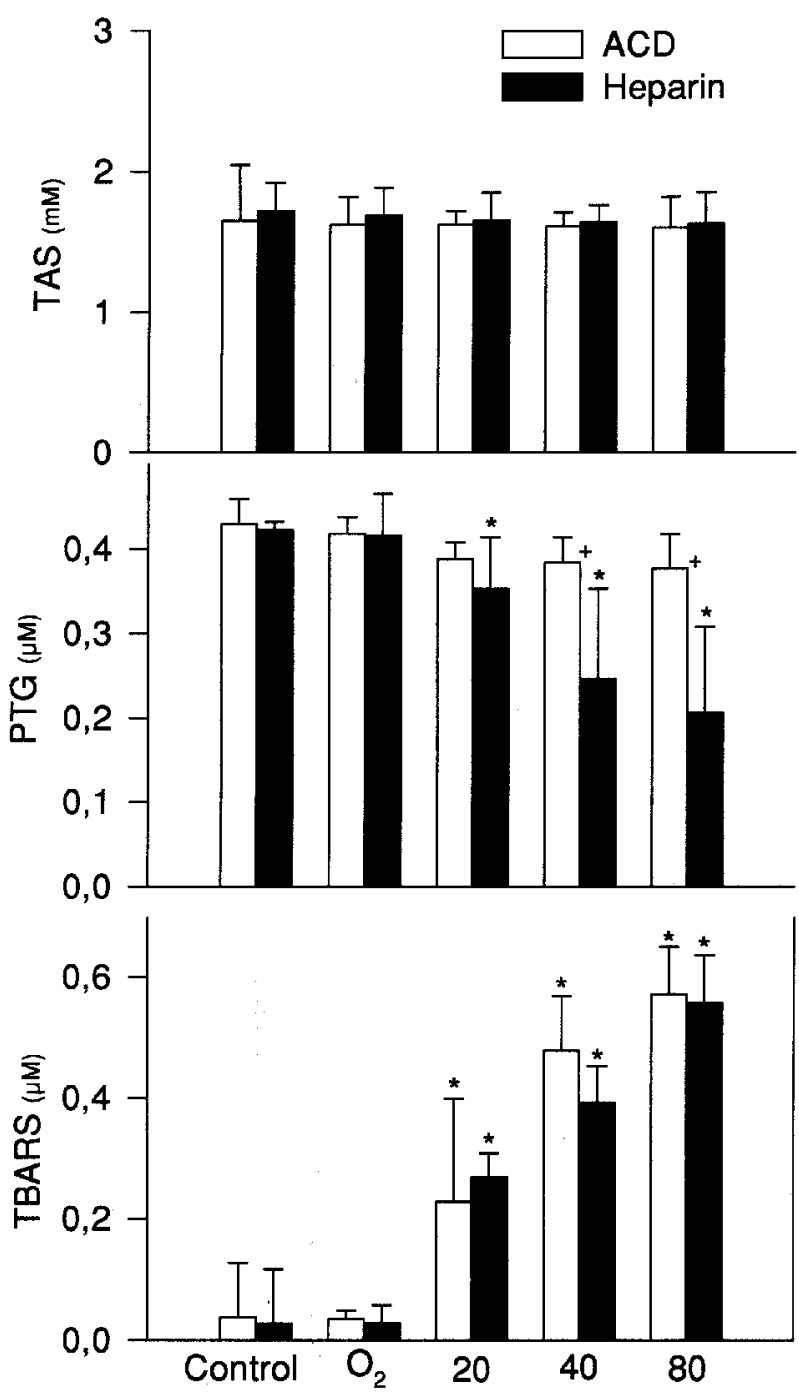

FIG. 1. Effect of $30 \mathrm{sec}$ exposure of either $\mathrm{O}_{2}$ or $\mathrm{O}_{2}-\mathrm{O}_{3}(20,40$ and $80 \mu \mathrm{g} / \mathrm{ml} \mathrm{perml} \mathrm{of} \mathrm{plasma)} \mathrm{on} \mathrm{total} \mathrm{antioxidant} \mathrm{status}$ (TAS), protein thiol group (PTG) and thiobarbituric acid reactive substances (TBARS) of the same human platelet rich plasma samples collected either in heparin or in ACD. The statistical significance has been indicated with a $\left(^{*}\right)$ for intergroup and with a (+) for intragroup analysis.

plasma samples were diluted 1:5. Immunoassay of IL8 was carried out using Cytoscreen kit produced by Biosource International (Camarillo, CA, USA). Plasma samples were diluted 1:1 with the appropriate diluent. A 3-cycle automatic washing was routinely performed. Samples have been tested at least in duplicate against the appropriate standards.

\section{Statistical analysis}

Results obtained from five donors have been expressed as the mean \pm the standard deviation of the mean (SD). A software package was used for data collection and statistical analys is (Statview SE, Abacus Concepts Inc., Berkeley, California). The significance of the differences between the means at different 


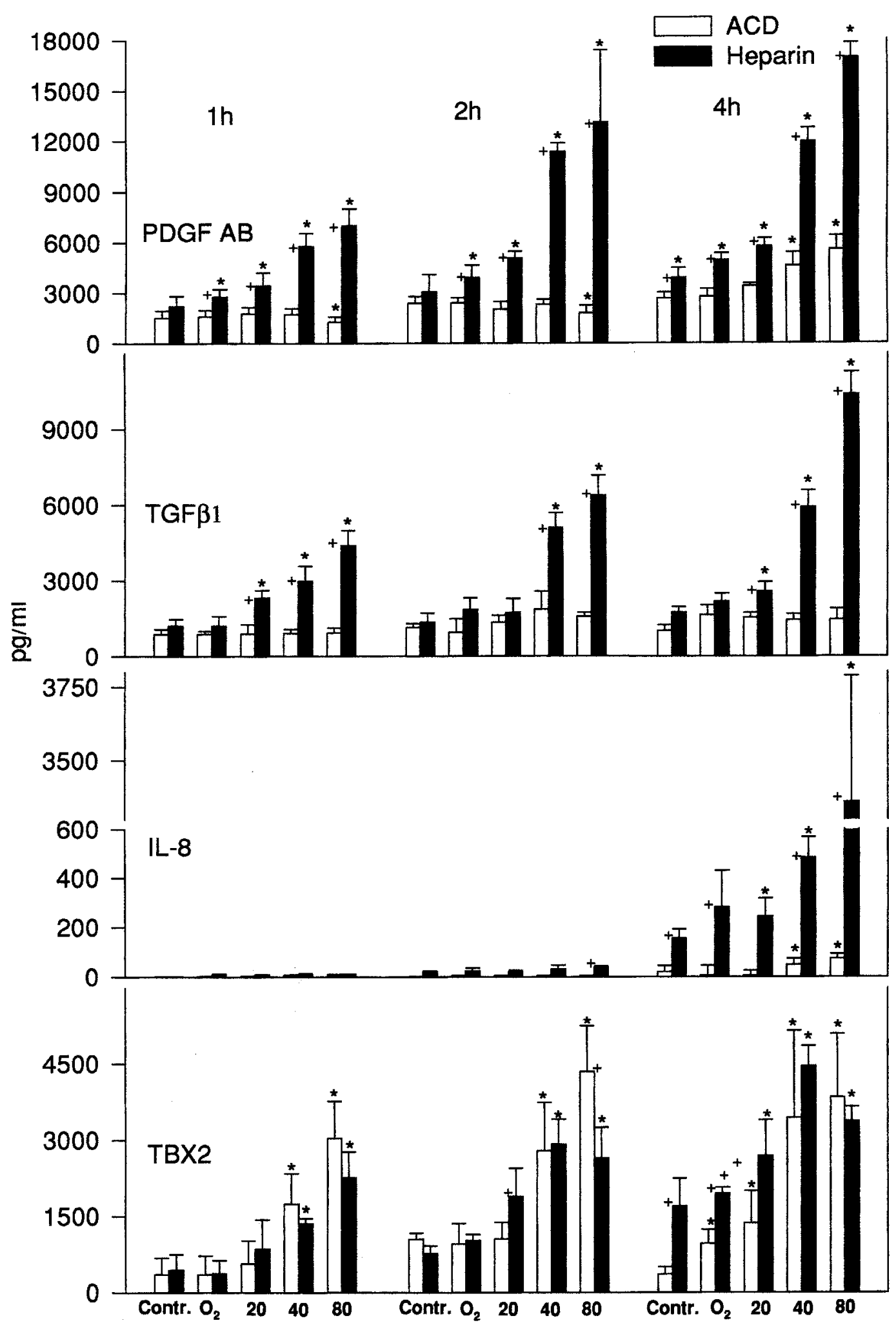

FIG. 2. Release of factors from human platelets during 1, 2 and $4 \mathrm{~h}$ incubation. The same PRP samples collected either in heparin or ACD were either not exposed (control), or exposed to $\mathrm{O}_{2}$ alone, or $\mathrm{O}_{2}-\mathrm{O}_{3}$ at 20,40 and $80 \mu \mathrm{g} / \mathrm{ml}$ concentration for $30 \mathrm{sec}$ before incubation. The statistical significance has been indicated with a $\left(^{*}\right)$ for intergroup and with a $(+)$ for intragroup analysis. 
times in each group was analysed by one-way analysis of variance (ANOVA). The significance of the differences between means for the two groups at different times was analysed by Student's $t$-test. The level of statis tical signific ance was set at $p<0.05$ for both inter and intrag roups analysis.

\section{Results}

Particularly PTG values decreased in approximate relation with the $\mathrm{O}_{3}$ concentration while TBARS values increased several folds (Fig.1). Moreover we have observed that oxidation of PTG is far higher in heparinised that $\mathrm{Ca}^{2+}$ chelated samples suggesting that physiological $\mathrm{Ca}^{2+}$ levels favour ROS activity. Indeed intragro up analys is showed a significant difference at a medium $(40 \mu \mathrm{g} / \mathrm{ml})$ and at a high $(80 \mu \mathrm{g} / \mathrm{ml})$ $\mathrm{O}_{3}$ concentration.

Fig.2 shows the strikingly and significant different release of PDGF AB, TGF $\beta 1$ and IL-8 from heparinised in comparison to $\mathrm{Ca}^{2+}$ chelated PRP samples. For the first two cytokines the difference is clear at all times, while for IL-8 it becomes evident only after 4 hours of incubation. As far as the release ofTXB2 is concerned, heparin does not appear to have a determinant role and both anticoagulants have yielded significant differences after ozonation of PRPs.

\section{Discussion}

A modified form of AHT, by irradiating blood with ultraviolet light, was firstly proposed by Wehrli and Ste inbart ${ }^{10}$ but AHT became popular after Wolff ${ }^{11}$ had show $n$ that direct exposure of blood to a know $n$ dose of $\mathrm{O}_{2}-\mathrm{O}_{3}$ was very simple, practical and free of risk of contamination. Since that time, countless $\mathrm{O}_{3}$-AHT sessions have been performed in Europe and in spite of a lack of double-blind, rando mised studies, it seems that this approach can be useful in vascular diseases, particularly in chronic limb ischemia. Rokitansky et $a l^{12}$ and Werkmeister ${ }^{13}$ had shown that even at late stages (III and IV grade) of the disease, $\mathrm{O}_{3}$-AHT, combined to topic application of ozone, can spare amputation and favour healing of torpid ulcers and necrotic areas. It is unfortunate that the results of these studies have been reported in a rather anecdotal form, so that during a revision ${ }^{14-15}$ of this field, it was pointed out that not only it is urgent to perform controlled studies but to clearly understand mechanisms of action and explain why $\mathrm{O}_{3}$-AHT enhances healing of ulcers.

A first important point that has never been clarified was which type of anti-coagulant: heparin or the usual sodium citrate would be more suitable. Indeed in a previous work ${ }^{1}$, we have show $\mathrm{n}$ that heparin, in the presence of $\mathrm{O}_{3}$, can promote platelet aggregation while, in contrast, $\mathrm{Ca}^{2+}$ chelation is practically ineffective. We then went to suspect that promotion of aggregation would favour the release of an array of intracellular components from platelets and we thought worth while to carry out a preliminary investigation.

We have now shown that two important healing factors, namely PDGF and TGF $\beta 1$, increase markedly during incubation particularly in heparinised PRP samples exposed to 40 and $80 \mu \mathrm{g} / \mathrm{ml}$ of $\mathrm{O}_{3}$. If this happens in vivo, after reinfusion of ozonated blood in patients with chronic limb ischemia, it may indeed favour healing of necrotic ulcers. However, this assumption must be tempered by the previous finding ${ }^{1}$ that platelet aggregation corresponds to either $20 \pm 6 \%$ or as much as $68 \pm 14 \%$ for $\mathrm{O}_{3}$ concentrations of either 40 or $80 \mu \mathrm{g} / \mathrm{ml}$, respectively. The forme $\mathrm{O}_{3}$ concentration still does allow an important release of growth factors with no risk of blood coagulation and therefore may represent the optimal $\mathrm{O}_{3}$ concentration.

The fairly late release of IL-8 has been interpreted as due to the time lag necessary for the synthesis. It is known that induction of IL-8 by $\mathrm{O}_{3}$, while is promoted by a temporary rise of $\mathrm{H}_{2} \mathrm{O}_{2}{ }^{14-16}$ in cytoplasmic water via the activation of nuclear factor (NF) $\mathrm{kB}$, is inhibited by ROS scavengers. ${ }^{17}$ As this chemokine is capable of initiating the chemotactic gradient that draws leukocytes from circulation into tissues, it may exert the additional role of favouring phagocytosis of bacteria and necrotic tissue present in torpid ulcers.

Release of TXB2, as the stable compound derived from thromboxane A2, ap pears as a drawback but we cannot draw a conclusion unless we carry out determination of other eicosanoids such as prostaglandin E2 and prostacyclin that induce vasodilation and inhibit aggregation. By using endothelial cells, work now in progress aims to clarify the role of $\mathrm{O}_{3}$ activation of cyclooxygenase and nitric oxide synte thase.

On the basis of these results, we would like to evaluate comparatively the effectiveness of AHT in patients with chronic limb ischemia treated with either citrated or heparinised blood exposed to the mild $\mathrm{O}_{3}$-AHT concentration of $40 \mu \mathrm{g} / \mathrm{ml}$.

ACKNOWLEDGMENTS: This work has been supported by Murst grant ( $40 \%$ national and $60 \%$ local funds). The careful preparation of the manuscript by Mrs. Patrizia Marrocchesi is grate fully acknowledged.

\section{References}

1. Bocci V, Valacchi G, Rossi R, Giustarini D, Paccagnini E, Pucci AM, Di Simplicio P. Studies on the biological effects of ozone: 9. Effects of ozone on human platelets. Platelets 1999: 10: 110-6

2. Iuliano L, Colavita AR, Leo R, Praticò D, Violi F. Oxygen free radicals and platelet activation. Free Rad Biol Med 1997: 22: 999-1006

3. Bocci V. Ozone as a bioregulator. Pharmacology and toxicology of ozonetherapy today. J Biol Regulat Homeost Agent 1996: 10: 31-53

4. Ledent E, Wasteson $\AA$, Berlin G. Grow th factor release during preparation and storage of platelet concentrates. Vox Sang 1995: 68: 205-9

5. Kunz D, Luley C, Heim MU, Böck M. Transforming grow th factor sym is increased in plasma of patients with hematologic malignancies after transfusion of platelet concentrates. Transfusion 1998: 38: 156-9 
6. Wadhw a M, Seghatchian MJ, Lubenko A, Contre ras M, Dilger P, Bird C, Thorpe R. Cytokine levels in platelet concentrates: quantitation by bioassays and immunoassays. Brit J Haematol 1996: 93: 225-34

7. Pompella A, Maellaro E, Casini AF, Ferrali M, Ciccoli L. Measurement of lipid peroxidation in vivo: a comparison of different procedures. Lipids 1987: 22: 206-11

8. Rice-Evans C, Miller NJ. Total antioxidant status in plasma and body fluids. In: Methods in Enzimology. New York: Academic Press, Inc., 1994: 279-93

9. Hu M-L. Measurement of protein thiol groups and glutathione in plasma. In: Methods in Enzimology. New York: Academic Press, Inc., 1994: 380-5

10. Wehrli F, Steinbart H. Erfahrungen mit der Haematogenen Oxydations The rapie (HOT). Ars Medici 1954: 10: 44-51

11. Wolff HH. Das medizinische Ozon. Theoretische Grundlagen, Therape utische Anwendungen. Heidelberg, 1979

12. Rokitansky O, Rokitansky A, Steiner I, Trubel W, Viebahn R, Washüttl J. Die Ozontherapie bei peripheren, arte riellen Durchblutungsstörungen: Klinik, biochemische und blutgasanalytische Untersuchungen. Wasser. Berlin: Ozon-Weltkongress, 1981: 53-75
13. Werkmeister H. Dekubitalgeschwüre und die Behandlung mit der OzonUnterdruckbegasung. E. G. Beck, R. Viebahn, eds. Ozon-Handbuck. Grundlage n. Prävention. Therapie. Landsberg/Lech: Ecomed, 1995:V-7.1 $1-22$

14. Bocci V. Ozone as a bioregulator. Pharmacology and toxicology of ozonetherapy today. J Biol Regulat Homeost Agent 1996: 10: 31-53

15. Bocci V. Is ozonetherapy therapeutic? Perspect Biol Med 1998: 42: $131-43$

16. Jaspers I, Flescher E, Chen LC. Ozone-induced IL-8 expression and transcription factor binding in respiratory epithelial cells. Amer J Physio 1997: 272: L504-11

17. DeForge LE, Fantone JC, Kenney JS, Remick DG. Oxygen radical scavengers selectively inhibit interleukin 8 production in human whole blood. J Clin Invest 1992: 90: 2123-9

\section{Received 4 July 1999;}

accepted (revised) 2 August 1999 


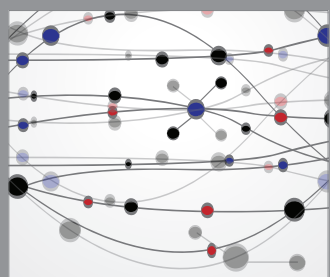

The Scientific World Journal
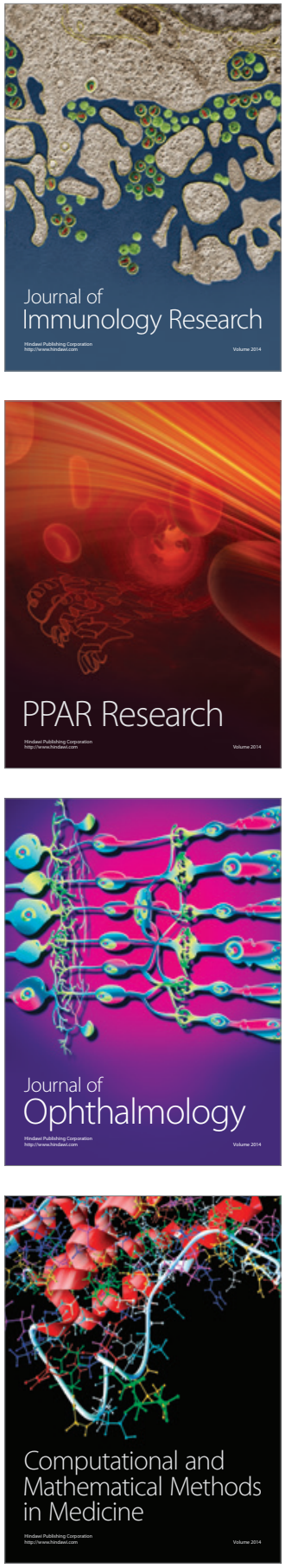

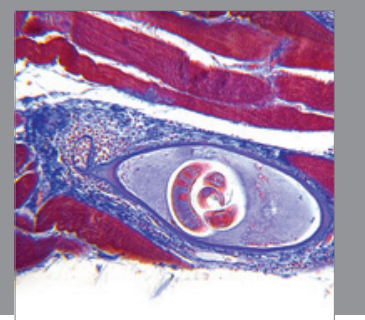

Gastroenterology

Research and Practice
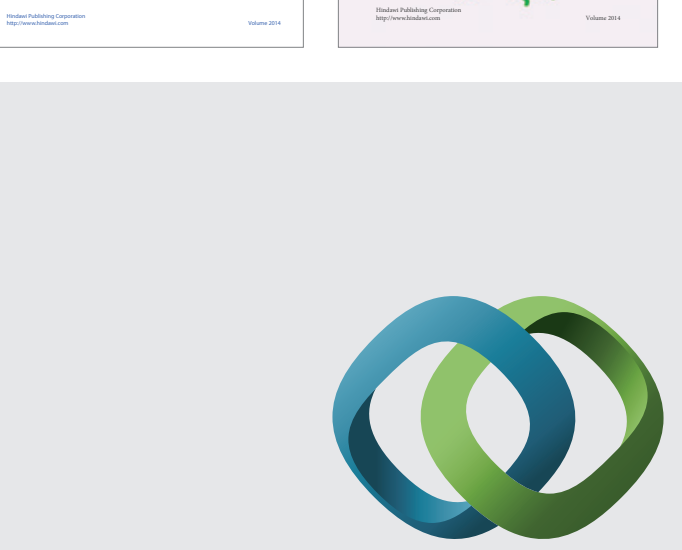

\section{Hindawi}

Submit your manuscripts at

http://www.hindawi.com
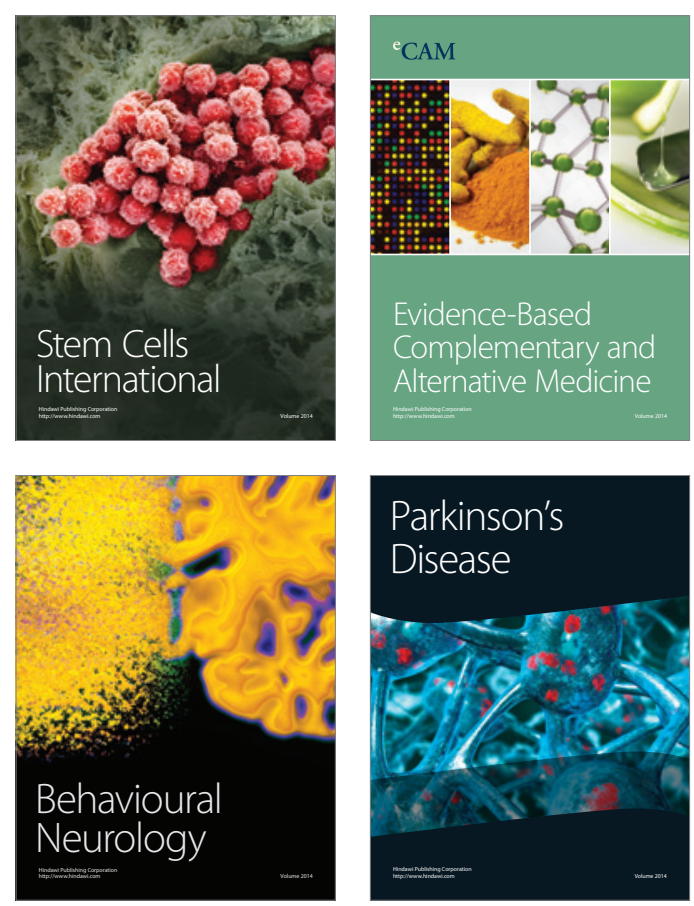

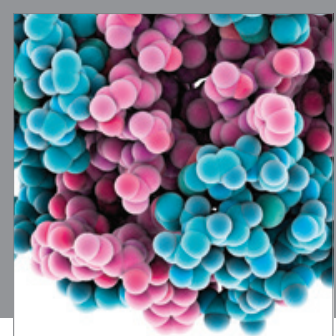

Journal of
Diabetes Research

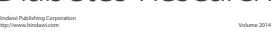

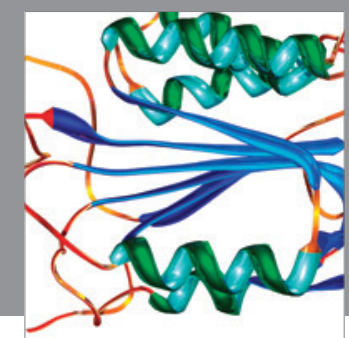

Disease Markers
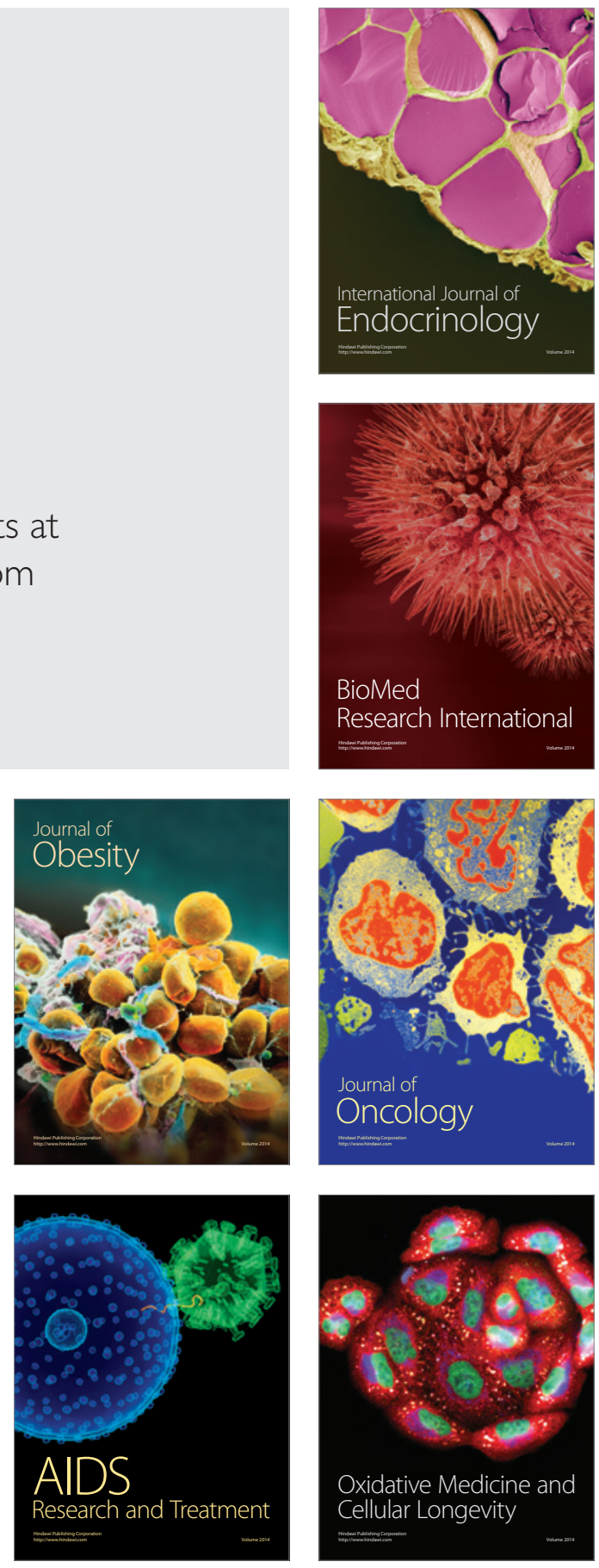